\title{
Aquaporin Membrane Channels in Oxidative Stress, Cell Signaling, and Aging: Recent Advances and Research Trends
}

\author{
Grazia Tamma ${ }^{D},{ }^{1}$ Giovanna Valenti ${ }^{1},{ }^{1}$ Elena Grossini, ${ }^{2}$ Sandra Donnini, ${ }^{3}$ \\ Angela Marino $\mathbb{D}^{4},{ }^{4}$ Raul A. Marinelli, ${ }^{5}$ and Giuseppe Calamita ${ }^{1}{ }^{1}$ \\ ${ }^{1}$ Department of Biosciences, Biotechnologies and Biopharmaceutics, University of Bari Aldo Moro, Bari, Italy \\ ${ }^{2}$ Department of Translational Medicine, University of Eastern Piedmont, Novara, Italy \\ ${ }^{3}$ Department of Life Sciences, University of Siena, Siena, Italy \\ ${ }^{4}$ Department of Chemical, Biological, Pharmaceutical and Environmental Sciences, University of Messina, Messina, Italy \\ ${ }^{5}$ Instituto de Fisiología Experimental, CONICET, Facultad de Ciencias Bioquímicas y Farmacéuticas, Universidad Nacional de \\ Rosario, Rosario, Santa Fe, Argentina
}

Correspondence should be addressed to Grazia Tamma; grazia.tamma@uniba.it and Giuseppe Calamita; giuseppe.calamita@uniba.it

Received 19 October 2017; Revised 29 January 2018; Accepted 20 February 2018; Published 27 March 2018

Academic Editor: Mark Crabtree

Copyright ( 2018 Grazia Tamma et al. This is an open access article distributed under the Creative Commons Attribution License, which permits unrestricted use, distribution, and reproduction in any medium, provided the original work is properly cited.

\begin{abstract}
Reactive oxygen species (ROS) are produced as a result of aerobic metabolism and as by-products through numerous physiological and biochemical processes. While ROS-dependent modifications are fundamental in transducing intracellular signals controlling pleiotropic functions, imbalanced ROS can cause oxidative damage, eventually leading to many chronic diseases. Moreover, increased ROS and reduced nitric oxide (NO) bioavailability are main key factors in dysfunctions underlying aging, frailty, hypertension, and atherosclerosis. Extensive investigation aims to elucidate the beneficial effects of ROS and NO, providing novel insights into the current medical treatment of oxidative stress-related diseases of high epidemiological impact. This review focuses on emerging topics encompassing the functional involvement of aquaporin channel proteins (AQPs) and membrane transport systems, also allowing permeation of NO and hydrogen peroxide, a major ROS, in oxidative stress physiology and pathophysiology. The most recent advances regarding the modulation exerted by food phytocompounds with antioxidant action on AQPs are also reviewed.
\end{abstract}

\section{Introduction}

Reactive oxygen species (ROS) are unstable reactive molecules, physiologically produced by xanthine oxidase, nicotinamide adenine dinucleotide phosphate oxidase, lipoxygenases, and mitochondria $[1,2]$. Though oxygen is peremptory for life, imbalances between antioxidant defense mechanisms, overproduction of ROS, or incorporation of free radicals from the environment to living systems lead to oxidative stress. ROS and other reactive species are implicated in a large spectrum of biological conditions, such as mutation, tumorigenesis, degenerative diseases, inflammation, aging, frailty, and development [3]. ROS exert a dual role as both deleterious and beneficial species, the latter being of pivotal importance as signaling molecules. At physiological levels, ROS can improve cellular activities as they are involved in the control of the chemical balance and synaptic plasticity [4], whereas an excess amount of ROS can damage the endothelium, leading to alteration of the intracellular reduction-oxidation homeostasis [5].

Among various mechanisms, the uncoupling of nitric oxide synthase (NOS) in vascular cells has also widely been reported to be involved in ROS generation. In that event, NOS is turned into a peroxynitrite generator, leading to detrimental effects on vascular function, due to lipidic peroxidation [6]. Furthermore, superoxide anions can modify endothelial function by reducing nitric oxide (NO) biosynthesis and bioavailability [7]. This issue is of particular 
relevance since changes in NO release could play an important role in endothelial function maintenance, in addition to regulating proliferation of smooth muscle cells, leukocyte adhesion, platelet aggregation, angiogenesis, thrombosis, vascular tone, and hemodynamics. Hence, endothelial dysfunction, a predictor of several cardiovascular diseases (CVDs), is caused by imbalance between vasodilating and vasoconstricting agents, including NO, endotheliumderived hyperpolarizing factor, prostacyclin, or vasoconstrictive factors such as thromboxane $\left(\mathrm{TXA}_{2}\right)$ and endothelin-1 (ET-1) [8].

$\mathrm{NO}$ is a gas which plays an important role in blood pressure modulation due to its signaling action on renal, cardiovascular, and central nervous system functions [9]. The role of $\mathrm{NO}$ in vascular homeostasis also comes from the negative regulation on coagulation and inflammation operated by this signaling molecule.

Throughout the years, ROS and NO have been widely considered to enter cells by freely diffusing through the cell membrane lipid bilayer and not via specific transporters or channels. This notion has been challenged by the discovery of new membrane transport functions, especially those exerted by aquaporins (AQPs), a family of membrane channel proteins widespread in nature $[10,11]$. Transport of $\mathrm{NO}$ and ROS by AQPs would be required for cell homeostasis to play a critical role in maintaining endothelial function.

This review focuses on an emerging topic, the functional involvement of AQPs in ROS membrane transport, with specific regard to the movement of hydrogen peroxide and NO into and out of cells, in both health and oxidative stressinduced diseases. The emerging information and research trends regarding the modulation exerted by food phytocompounds with antioxidant action on the expression and function of AQPs are also reviewed.

\section{Exogenous and Endogenous Source of Oxidants}

Reactive species (RS) derive from either endogenous or exogenous sources. Prolonged exercise, ischemia, inflammation, infection, cancer, and aging correlate with production of free radicals. Production of ROS and reactive nitrogen species (RNS) may occur through enzymatic and nonenzymatic reactions $[12,13]$. Among enzymatic processes, NADPH oxidase (NOX), xanthine oxidase, and peroxidases play a pivotal role in free radical generation. For example, NOX catalyzes the production of superoxide [14], which represents a master substrate for generation of other RS, such as hydrogen peroxide $\left(\mathrm{H}_{2} \mathrm{O}_{2}\right)$, hydroxyl radical $\left(\mathrm{OH}^{\bullet}\right)$, peroxynitrite $\left(\mathrm{ONOO}^{-}\right)$, and hypochlorous acid $(\mathrm{HOCl})$. The latter is synthesized in neutrophils by myeloperoxidase, an enzyme oxidizing chloride ions when $\mathrm{H}_{2} \mathrm{O}_{2}$ is present $[15,16]$. Nitric oxide $\left(\mathrm{NO}^{\bullet}\right)$ is generated in many tissues and results from the oxidation of L-arginine to citrulline through the action of nitric oxide synthase [17], as reported above.

Nonenzymatic reactions can also occur during oxidative phosphorylation in mitochondria, the main RS production site inside the cell [18]. The leakage of electrons at complex
I, complex II, or complex III associates with superoxide production. In the mitochondrial matrix and in the cytosol, superoxide can be converted into $\mathrm{H}_{2} \mathrm{O}_{2}$ by superoxide dismutase and further detoxified by catalases. In addition, ROS stimulates the generation and the release of other RS, thereby causing a vicious circle due to increased permeability of mitochondrial pores by ROS resulting in mitochondrial defects leading to release of further RS [19].

Alternatively, RS also result from reaction with organic compounds subjected to ionizing radiations. Indeed, high doses of ionizing radiation increase the production and release of inflammatory chemokines and RS that, in concert, promote tissue injury [20].

Exogenous RS can originate from water and air pollution, cigarette smoke, pesticides, dioxin, and several drugs. Once in the body, these different compounds are metabolized, generally in the liver, generating free radicals.

\section{Aquaporins, Membrane Channel Proteins of Pleiotropic Relevance}

Aquaporins (AQPs) are channel proteins widely present in living organisms where they were initially reported to facilitate the transport of water and certain neutral solutes across biological membranes [21, 22]. Mammals possess thirteen distinct AQPs (AQP0-12) that are roughly subdivided into orthodox aquaporins (AQP0, AQP1, AQP2, AQP4, AQP5, AQP6, and AQP8) and aquaglyceroporins (AQP3, AQP7, AQP9, and AQP10). Orthodox AQPs were initially described to conduct only water, whereas aquaglyceroporins were shown to transport water and some small neutral solutes, particularly glycerol. These peculiarities did not apply to AQP11 or AQP12, due to their distinct evolutionary pathway and primary sequence distinctions, the reason why they have been indicated as unorthodox aquaporins [23]. The transport properties and subcellular localization of AQP11 and AQP12 remain unclear and a matter of debate. The functional subdivision of AQPs has become more articulated in the light of transport properties reported in recent years. Some AQPs are also able to conduct $\mathrm{H}_{2} \mathrm{O}_{2}$ and/or ammonia [24], and, due to these biophysical properties, they are also denoted as peroxiporins $[25,26]$ and ammoniaporins (or aquaammoniaporins) [25, 27, 28], respectively. The currently identified mammalian AQP homologues allowing passive diffusion of considerable amounts of $\mathrm{H}_{2} \mathrm{O}_{2}$ are AQP1, AQP3, AQP5, AQP8, and AQP9 [29]. AQPs also facilitate permeation of gases such as $\mathrm{CO}_{2}, \mathrm{NO}$, or $\mathrm{O}_{2}[11,30,31]$, features that have raised a lot of interest due to the potential physiological relevance they may have in permeating gases of biological relevance. This feature would add more knowledge to the physiological importance of gas channels in nature [32].

Expression and modulation of AQPs in all body districts are the subject of intense investigation around the world. Important roles have already been ascribed to this family of membrane channels, in both health and disease [21, 22, 33] (Table 1). 
TABLE 1: Functional relevance of mammalian aquaporins in health and disease.

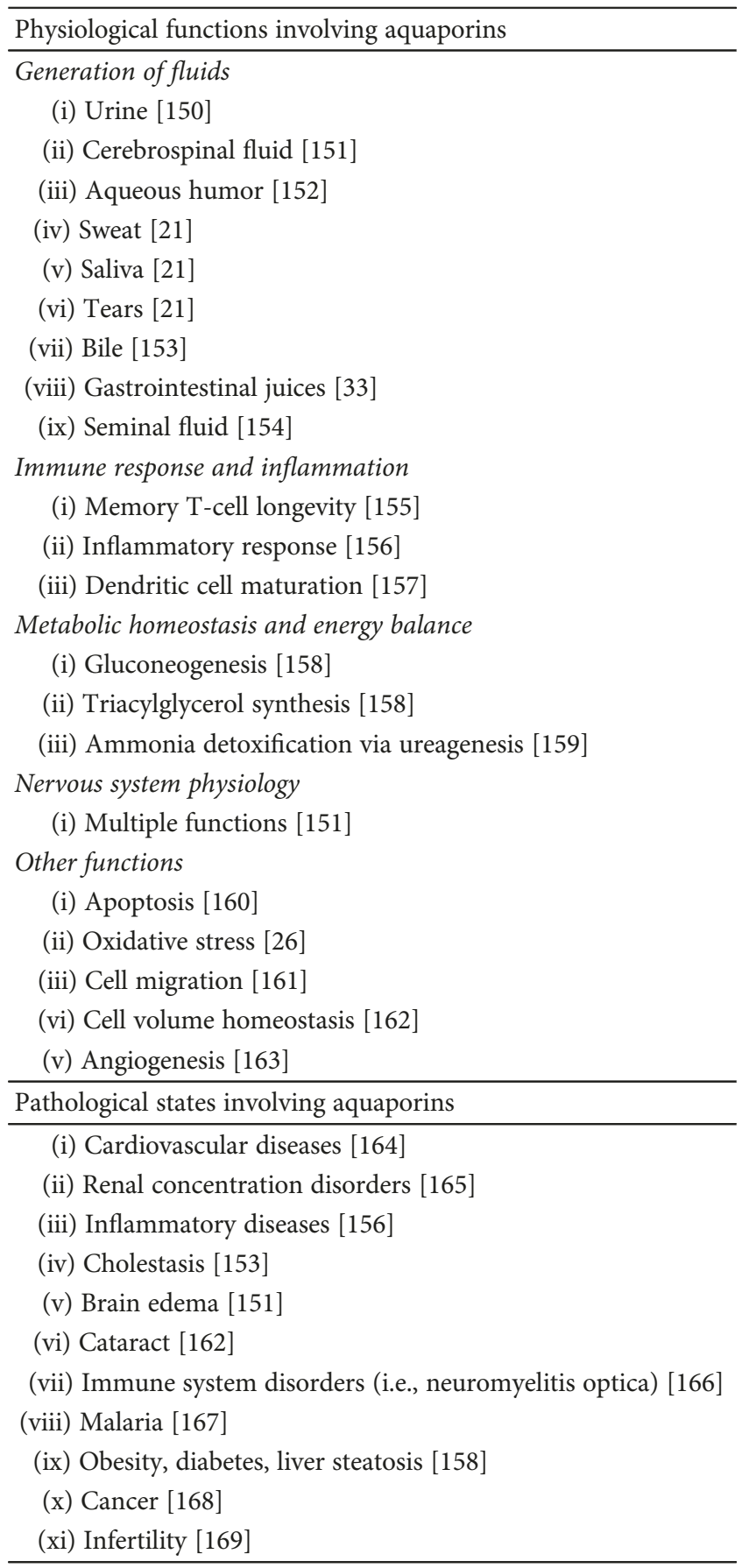

\section{Involvement of Aquaporins in the Transport System of Reactive Species}

4.1. Aquaporin-8 as Peroxiporin Mediating Mitochondrial $\mathrm{H}_{2} \mathrm{O}_{2}$ Release in Hepatocytes. $\mathrm{H}_{2} \mathrm{O}_{2}$ is a major ROS constantly generated in mitochondria by the aerobic metabolism. Respiratory chain-linked $\mathrm{H}_{2} \mathrm{O}_{2}$ is produced by enzymatic dismutation of superoxide radicals [34]. Complex I generates superoxide within the mitochondrial matrix, whereas complex III generates superoxide in the intermembrane space $[34,35]$. Hepatic mitochondria are not only important sources for ROS but also important key targets for their potential damage. Under physiological conditions, $\mathrm{H}_{2} \mathrm{O}_{2}$ is the only ROS that can move out of the mitochondria into the cytoplasm and function as a second messenger in signal transduction pathways [35, 36]. Under oxidative stress, high $\mathrm{ROS}\left(\mathrm{H}_{2} \mathrm{O}_{2}\right)$ levels can induce loss of mitochondrial membrane potential and mitochondrial dysfunction with the resulting triggering of cell death mechanisms $[37,38]$.

$\mathrm{H}_{2} \mathrm{O}_{2}$ had been long thought to be freely diffusible across cellular membranes, a notion that has been challenged by both the existence of $\mathrm{H}_{2} \mathrm{O}_{2}$ gradients across biological membranes $[39,40]$ and the finding that membrane permeability is a rate-limiting factor in $\mathrm{H}_{2} \mathrm{O}_{2}$ elimination by mammalian cells [41]. Limited diffusion of $\mathrm{H}_{2} \mathrm{O}_{2}$ across mitochondrial membranes has also been suggested [42]. Hence, a proteinfacilitated diffusional pathway for $\mathrm{H}_{2} \mathrm{O}_{2}$ across membranes was proposed $[40,42] . \mathrm{H}_{2} \mathrm{O}_{2}$ size and chemical and physicochemical properties are similar to those of water [40], which may explain $\mathrm{H}_{2} \mathrm{O}_{2}$ passage through channel membrane proteins such as AQPs. Accordingly, initial studies in reconstituted yeast [10] and transfected mammalian cells [43] indicate that AQP8 and some other members of the mammalian AQP family facilitate $\mathrm{H}_{2} \mathrm{O}_{2}$ passage across plasma membranes. Thus, AQP8 is able to function as peroxiporin.

An initial study demonstrated that AQP3 is required for (NOX)-derived $\mathrm{H}_{2} \mathrm{O}_{2}$ signaling [43]. More recent studies in diverse nonhepatic cells have reported that plasma membrane AQP8 transports NOX-generated $\mathrm{H}_{2} \mathrm{O}_{2}$ that participates in intracellular signal transduction pathways [44-47]. In HeLa cells, AQP8 plays a key role in the epidermal growth factor- (EGF-) induced entry of $\mathrm{H}_{2} \mathrm{O}_{2}$, which in turn initiates intracellular signaling by tyrosine phosphorylation of target proteins [44]. In $\mathrm{B}$ lymphocytes, AQP8-mediated $\mathrm{H}_{2} \mathrm{O}_{2}$ transport has been reported to induce cell activation and differentiation [45], whereas in leukemia cells, it has been found to induce proliferation pathways $[46,47]$.

In hepatocytes, plasma membrane AQP8 is exclusively expressed on the bile canalicular domain [48]. Therefore, AQP8 cannot be involved in the intracellular transport of $\mathrm{H}_{2} \mathrm{O}_{2}$ generated by NADPH oxidases at sinusoidal plasma membranes. AQP8 is also expressed in the inner mitochondrial membranes of some cells, including hepatocytes $[49,50]$. Experimental evidence in human hepatocyte carcinoma HepG2 cells suggests that mitochondrial AQP8 (mtAQP8) facilitates the diffusional efflux of $\mathrm{H}_{2} \mathrm{O}_{2}$ [51]. A similar observation was made studying mitochondrial AQP8b, the marine teleost orthologue of human AQP8 [52]. As reviewed below, the involvement of an mtAQP8mediated $\mathrm{H}_{2} \mathrm{O}_{2}$ transport in normal human spermatozoa functioning has also been suggested [53].

The knockdown of mtAQP8 expression in HepG2 cells markedly reduces the release of mitochondrially generated $\mathrm{H}_{2} \mathrm{O}_{2}$, and the resulting mitochondrial ROS accumulation induces mitochondrial depolarization via the mitochondrial permeability transition mechanism and reduced ATP levels [51]. Interestingly, the immunological blockage of AQP8bmediated mitochondrial $\mathrm{H}_{2} \mathrm{O}_{2}$ efflux in marine spermatozoa 
also causes ROS accumulation, mitochondrial depolarization, and decreased ATP production [52].

The oxidant-induced mitochondrial dysfunction in HepG2 cells causes loss of viability by activating a necrotic death pathway [51, 54]. Interestingly, mtAQP8 silencing causes a minor loss of viability in human hepatoma HuH-7 cells but does not affect viability in neither in normal rat hepatocytes nor in the nonneoplastic human cell lines, renal HK-2, and Chang liver cells [54]. Therefore, carcinoma cells might be particularly susceptible to defective mtAQP8 expression. As the loss of viability in mtAQP8-knockdown HepG2 cells is prevented by the mitochondria-targeted antioxidant MitoTempol [51], a disparity in mitochondrial antioxidant defenses is likely to explain the observed differential susceptibility among mtAQP8-knockdown cells. Nevertheless, it is worth mentioning that, at least for total and reduced mitochondrial glutathione levels, there were no significant differences between HepG2, HuH-7, Chang liver cells, and rat hepatocytes (unpublished data from Raul A. Marinelli's laboratory). Further studies are needed to understand the mechanisms that actually cause differential death in mtAQP8-knockdown cells.

With the use of HeLa cells, the AQP8-mediated plasma membrane $\mathrm{H}_{2} \mathrm{O}_{2}$ transport has recently been reported to be functionally modulated under stress [55]. AQP8 permeability to $\mathrm{H}_{2} \mathrm{O}_{2}$ was reversibly inhibited, thus preventing intracellular ROS accumulation during oxidative stress [55]. To the best of our knowledge, as AQP8 expression has not been demonstrated in HeLa cell mitochondria [44, 56], it would be interesting to explore whether hepatocyte mtAQP8 is under this novel regulatory mechanism of cell survival during stress.

Another as-yet-unexplored area of research is the role that mtAQP8-mediated $\mathrm{H}_{2} \mathrm{O}_{2}$ may play in hepatocyte physiology. We have recently provided evidence suggesting that hepatocyte mtAQP8 expression can be modulated by cholesterol via sterol regulatory element-binding protein (SREBP) transcription factors; that is, mtAQP8 is upregulated in cholesterol-depleted cells and downregulated in cholesterolloaded cells [57]. As $\mathrm{H}_{2} \mathrm{O}_{2}$ has been described to stimulate hepatocyte cholesterogenesis via SREBPs [58], our finding might suggest that mtAQP8 plays a role in SREBPcontrolled cholesterol biosynthesis. For example, at low cellular cholesterol levels, SREBP-dependent mtAQP8 upregulation could facilitate the mitochondrial $\mathrm{H}_{2} \mathrm{O}_{2}$ release that would contribute to stimulating cholesterogenesis. Further studies are required to elucidate this issue.

4.2. AQP-Mediated $\mathrm{H}_{2} \mathrm{O}_{2}$ Transport Is Critical in Sperm Cell Motility and ROS Scavenging. The relevance of AQPmediated water and $\mathrm{H}_{2} \mathrm{O}_{2}$ transport in human sperm cells activity has been reported in a recent study investigating the expression, distribution, and role of AQP3, 7, 8, and 11 in subfertile compared with normospermic subjects [53]. The investigated AQPs were found to be implicated in sperm cell volume regulation and ROS scavenging, two functions of critical importance in sperm counts and motility. With the use of AQP blockers, it was suggested that chronic deficiency in AQP-mediated $\mathrm{H}_{2} \mathrm{O}_{2}$ permeability impairs ROS efflux out of sperm cells and reduces the detoxification efficiency, with consequent loss of sperm functionality. However, although coordinated action of AQPs has been reported to regulate sperm motility in the marine teleost seabream [59], further studies are needed to confirm the suggested pathophysiological relevance of AQPs in human male fertility. The specific $\mathrm{AQP}$ homologue that, among $\mathrm{AQP} 3,7,8$, and 11 , may account for sperm cell permeability to $\mathrm{H}_{2} \mathrm{O}_{2}$ remains elusive. AQP8 features one of the highest conductances to $\mathrm{H}_{2} \mathrm{O}_{2}$ among peroxiporins. However, the relevance of AQP8 as the major $\mathrm{H}_{2} \mathrm{O}_{2}$ membrane transport system in human sperm cells remains to be proved. A recent study using HeLa cells showed reduction of AQP-mediated water and $\mathrm{H}_{2} \mathrm{O}_{2}$ cell permeability following oxidative stress [60]. Interestingly, the diminution was prevented or reversed when the cells were treated with antioxidant phytochemical compounds.

\subsection{AQP3 Mediates Hydrogen Peroxide-Dependent} Intracellular Signaling, Responses to Environmental Stress, and Cell Migration. AQP3 is also reported to facilitate the uptake of $\mathrm{H}_{2} \mathrm{O}_{2}$ into mammalian cells [43]. Microimaging studies using peroxy yellow 1 methyl-ester (PY1-ME), a specific fluorescent probe for $\mathrm{H}_{2} \mathrm{O}_{2}$, showed $A Q P 3$-mediated uptake of $\mathrm{H}_{2} \mathrm{O}_{2}$ in HEK cells [43]. Moreover, it has been demonstrated that $\mathrm{T}$-cell migration towards chemokines is regulated by AQP3-facilitated transport of $\mathrm{H}_{2} \mathrm{O}_{2}$ that, in turn, stimulates Rho signaling [61]. In primary keratinocytes, $\mathrm{H}_{2} \mathrm{O}_{2}$ is required to stimulate NF- $\kappa \mathrm{B}$ signaling in response to TNF-alpha [62].

Conversely, oxidative signals seem to be important in controlling AQP3 expression. Chrysin and resveratrol, two antioxidant phytocompounds, have been reported to modulate the expression of AQP3 [63, 64]. Accordingly, severe ultraviolet A (UVA) irradiation causes a significant reduction in AQP3 expression secondary to increased oxidative stress [65]. In this regard, a negative correlation between AQP3 expression and age in sun exposed skin has been described, suggesting AQP3 as a biomarker of age-related skin alteration [66].

In the colon, AQP3 is expressed in the epithelial cells where changes in expression were found in response to inflammation, and AQP3-depleted mice experienced impaired recovery after chemical-induced colitis [67]. Interestingly, mice lacking AQP3 showed impaired healing of superficial wounds in the colon. This finding elucidates the signaling mechanism of extracellular $\mathrm{H}_{2} \mathrm{O}_{2}$ in colonic epithelium and suggests the implication of $\mathrm{AQP} 3$-mediated $\mathrm{H}_{2} \mathrm{O}_{2}$ transport in innate immune responses at mucosal surfaces [68]. AQP3-mediated $\mathrm{H}_{2} \mathrm{O}_{2}$ transport has also been described to control EGF signaling in epithelial cells [69], playing an important role in T-cell and breast cancer cell migration [70, 71]. However, the exact contribution of the AQP3-mediated $\mathrm{H}_{2} \mathrm{O}_{2}$ transport to these changes in cellular function remains to be fully elucidated. Involvement of AQP3 in trefoil peptide and EGF-mediated migration, a vital process in inflammatory bowel disease repair in case of excess free radical production, has also been recently shown [72]. 


\subsection{AQP1-Mediated Diffusion of NO in Vasorelaxation}

4.4.1. Endothelial NO Release and Oxidative Stress during Aging. With aging, endothelial cells (ECs) undergo considerable remodeling processes $[73,74]$. Increased endothelial permeability, alterations in the cytoskeleton, the appearance of $\beta$-galactosidase staining, and the expression of several cell cycle inhibitors [75] are also observed. Aging of ECs is associated with an increased release of vasoconstrictors, such as angiotensin II and endothelin, and a reduced release of vasodilators, such as NO and prostacyclin [76].

Among the above factors, NO bioavailability has been suggested to play a central role in maintaining endothelial function [77-79]. NO is the subject of extensive studies as one of the most relevant factors released by the endothelium, playing an outstanding role in maintaining vascular system function $[77,79-81]$. NO is produced by endothelial NO synthase (eNOS), which transfers electrons from nicotinamide adenine dinucleotide phosphate (NADPH) to the heme in the amino-terminal oxygenase domain. In this way, the substrate $\mathrm{L}$-arginine is oxidized to $\mathrm{L}$-citrulline and NO. Tetrahydrobiopterin (BH4) is an essential cofactor of eNOS exerting a key role in the progression of NO synthesis (Figure 1). NO formed by the vascular ECs diffuses to the adjacent cells, such as vascular smooth muscle cells (VSMCs), platelets, and leucocytes, where it exerts many of its beneficial actions, such as vasodilation, antithrombotic, anti-inflammatory, and antiproliferative effects [82]. Endothelium-derived NO is known to be particularly important to maintain normal vascular tone, endothelial function, and homeostasis [83], preventing the progression of age-related vascular disorders [80]. Decreased production of endothelium-derived NO during aging is commonly believed to be due to decreased eNOS activity characterizing senescent ECs [78]. In the peroxidative conditions associated with aging, superoxide anion $\left(\mathrm{O}_{2}{ }^{-}\right)$can also react with NO leading to the formation of peroxynitrites, which, in turn, can promote protein nitration and contribute to EC dysfunction and death $[84,85]$. Furthermore, enhanced oxidative stress can lead to eNOS "uncoupling" and cause endothelial dysfunction [86].

BH4 oxidation is one of the possible mechanisms of eNOS "uncoupling." Intracellular BH4 levels depend on the balance between its synthesis and degradation. In particular, oxidative stress may lead to excessive oxidation and depletion of BH4. As a consequence, the flow of electrons within NOS could be "uncoupled" from L-arginine oxidation and $\mathrm{O}_{2}{ }^{-}$ produced from the oxygenase domain [87]. Hence, eNOS would be converted to a superoxide-producing enzyme with reduced NO production and enhanced preexisting oxidative stress $[88,89]$.

4.4.2. AQP1 and NO Flow in Vascular Senescence and Atherosclerosis. Free diffusion (simple diffusion) through the phospholipid bilayer composing the plasma membrane had historically been assumed to be the only pathway whereby NO moves into or out of cells. Thus, based on the partition coefficient of NO between lipids and water [90, 91] rather than direct experimental assessment of NO diffusion across the cell membrane, $\mathrm{NO}$ was believed to cause vasodilation, antithrombotic, anti-inflammatory, and antiproliferative effects without need of facilitation by channels or transporters. This assumption was not confirmed after measurements of NO fluxes across reconstituted proteoliposomes and transfected cultured cells showing that, in addition to water, the AQP1 channel could conduct NO across plasma membranes and that the plasma membrane represents a significant barrier to NO diffusion [11]. Successively, with the use of thoracic aortas isolated from wild-type $\left(A q p^{+/+}\right)$and $A q p^{-1-}$ knockout mice, it was shown that AQP1 facilitates NO diffusion out of endothelial cells and NO influx into vascular smooth muscle cells, and that AQP1 conduction of NO is required for full expression of endothelium-dependent vasorelaxation [92]. Regarding vascular aging, changes in AQPs expression have been found in animal models of kidney-clip hypertension [11]. The trafficking of AQPs within cells has also been shown to change during aging, as observed in the parotid gland [93]. The suggested role of $\mathrm{AQPs}$ in vascular function regulation and senescence through modulation of NO diffusion across cell membranes opens a new avenue in understanding vascular senescence physiology and pathophysiology. Additional work is, however, needed since a discrepancy has been raised by a study reporting intact NO-dependent vasorelaxation in AQP1-depleted mice [94]. Vascular AQP1 expression was found to undergo positive regulation with the mediation of KLF2, the flow-responsive transcription factor Krüppel-like factor 2 that maintains an anticoagulant, anti-inflammatory endothelium with sufficient NO bioavailability [95]. Both in vitro and in vivo AQP1 expression was subjected to KLF2-mediated positive regulation by atheroprotective shear stress whereas it proved to be downregulated under inflammatory conditions. While suggesting that endothelial expression of AQP1 characterizes the atheroprotected, noninflamed vessel wall, this finding supports the putative continuous role of KLF2 in stabilizing the vessel wall via cotemporal expression of eNOS and AQP1, helping to prevent or counteract the pathogenesis of atherosclerosis.

\section{Role of Vasopressin/AQP2 Axis and Oxidative Stress in Aging}

Alterations in plasma osmolality and fluid body volume are observed in the elderly, making old people at high risk of developing disturbances of the water metabolism, which can give rise to several adverse effects. Aging blunts thirst and drinking responses, making older people more vulnerable to body fluid imbalance and dehydration [96], which can compromise cognitive function [97, 98]. Indeed, dehydration is a predisposing factor for confusion in long-term care residents [99]. Furthermore, plasma hypertonicity, a marker of dehydration, increases the risk of ischemic stroke in hospitalized patients [100] and may precipitate cerebral ischemic events in susceptible elderly individuals [101].

The major hormone regulating water metabolism in the body is vasopressin. Vasopressin is a 9-amino acid peptide that is secreted from the posterior pituitary in response to high plasma osmolality and hypovolemia. Vasopressin has important roles in circulatory and water homeostasis 


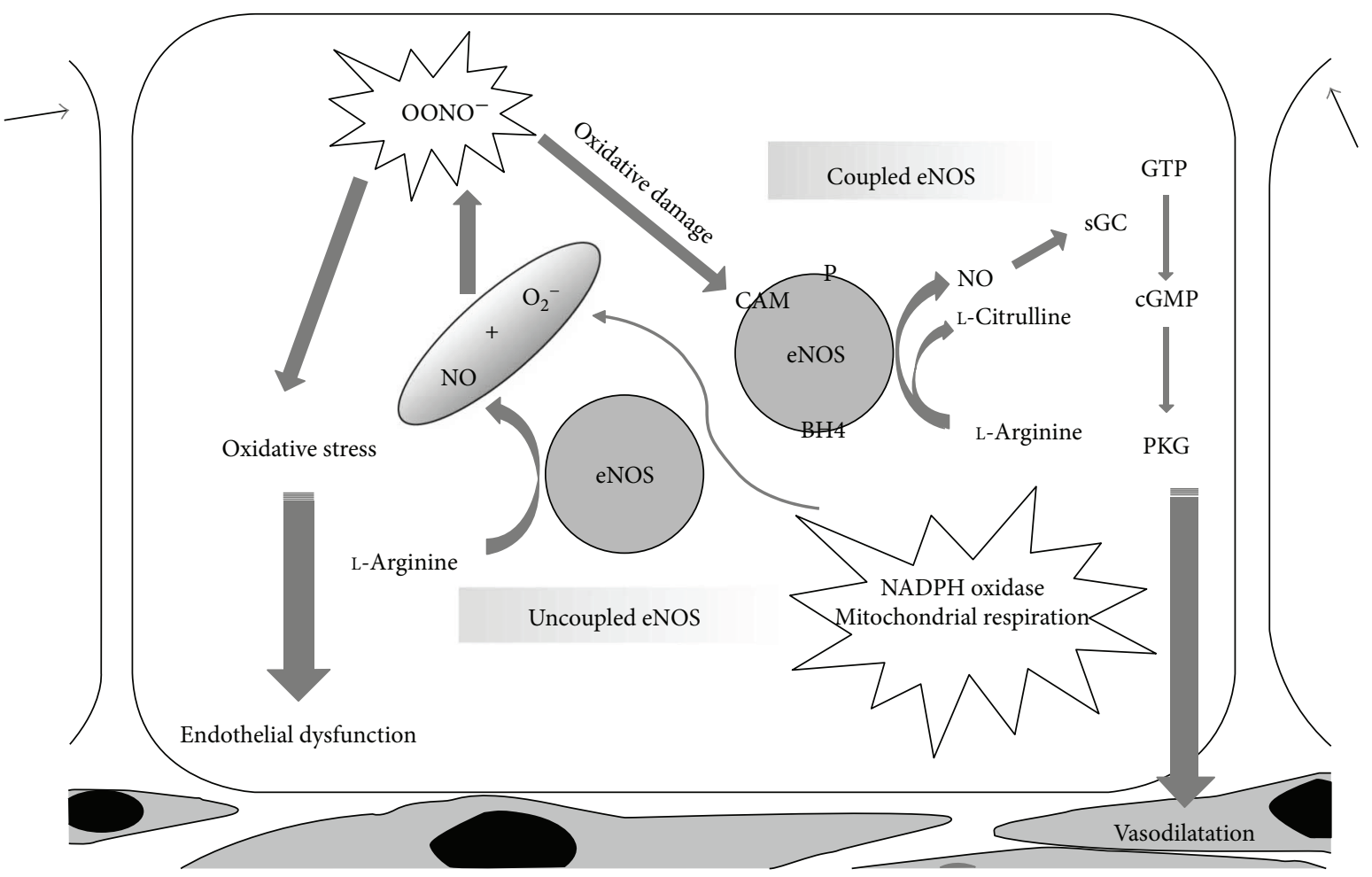

FIGURE 1: NO release by eNOS in physiological and peroxidative conditions. While "coupled" eNOS is involved in the physiological NO release underlying vasorelaxation, NO release by "uncoupled" eNOS is turned into $\mathrm{OONO}^{-}$(peroxynitrites) leading to an increase in oxidative stress with consequent endothelial dysfunction. ADMA: asymmetric dimethylarginine; Akt: protein kinase B; BH4: tetrahydrobiopterin; CAM: calmodulin; Cav-1: caveolin 1; eNOS: endothelial NO synthase; cGMP: cyclic guanosine monophosphate; GTP: guanosine triphosphate; GTPCH: guanosine triphosphate cyclohydrolase I; Hsp 90: heat shock protein 90; NADPH: nicotinamide adenine dinucleotide phosphate; NO: nitric oxide; sGC: soluble guanylate cyclase; PKG: protein kinase G.

mediated by vasopressin receptor subtypes V1a (vascular), V1b (pituitary), and V2 (vascular, renal). Therefore, agerelated dysfunction of the hypothalamic-neurohypophysealvasopressin axis can result in multiple abnormalities in several physiological systems that might promote a variety of morbidity such as cardiovascular and renal diseases [102, 103].

At the renal level, it has been observed that aging is accompanied by a parallel decrease in maximal urine concentrating ability [104]. Individuals aged 60-79 years show an approximately $20 \%$ reduction in maximum urine osmolality, a $50 \%$ decrease in the ability to conserve solute, and a $100 \%$ increase in minimal urine flow rate, when compared to younger age groups. Abnormalities in vasopressin secretion appear to be associated with the decrease in urine concentrating ability with aging: the abundance of many of the key transport proteins responsible for urine concentrating ability is reduced in the kidney medulla of aged rats [105]. The reductions in water, sodium, and urea transport protein abundances, along with their reduced response to water restriction, contribute to the reduced ability of aged rats to concentrate urine and conserve water [104].

The major mechanism by which vasopressin modulates water reabsorption is by regulating the trafficking of the vasopressin-sensitive water channel aquaporin-2 (AQP2) in collecting duct principal cells. Specifically, binding of vasopressin to the V2R increases cAMP levels, resulting in the activation of protein kinase A (PKA). PKA-dependent phosphorylation of the water channel AQP2, at S256, is essential to promote the translocation of AQP2-bearing vesicles from an intracellular pool to the apical plasma membrane [106]. Phosphoproteomic studies have demonstrated that, besides S256, vasopressin stimulation increases S264 and T269 but decreases the phosphorylation of S261 [107].

Several studies performed in animal models have shown that in aged rats, there is a large decrease in the level of AQP2 as well as of its phosphorylated form at S256, which can contribute to the reduced renal concentrating abilities $[105,108]$. Furthermore, AQP3 is reduced in aged rats, but no change in the expression of AQP1 and AQP4 has been detected in aged rats. This distinction in the regulation of AQPs abundance may be related to the fact that only AQP2 and AQP3 expressions are under control of vasopressin.

One possible therapy to overcome the decrease in AQP2 abundance in aging might be the administration of vasopressin. A recent study showed that desmopressin (dDAVP), a selective V2R agonist, administered to 10- and 30-monthold Wag/Rij rats, decreases urine output in both rat groups and leads to an increase in AQP2 and AQP3 abundance. These results suggest that a decrease in AQP2 and AQP3 expression levels partially accounts for the diminution in urinary concentrating ability in aging.

In general, due to an impaired ability to conserve water, in the elderly, there is a decrease in total body water content 
associated with a reduction of plasma volume. These changes make the elderly much more sensitive to water overload or dehydration resulting in abnormal movement of solutes and, thereby, increasing the possibility of developing hypoor hypernatremia.

However, an increase in vasopressin levels can also be found in aged people, where it induces water retention and hyponatremia and stimulates calcium release from bone, thus contributing to osteoporosis, as well as affecting the cardiovascular system and blood pressure, thus contributing to the development of hypertension.

For these diseases often associated with the elderly, vasopressin receptor antagonists represent a promising therapeutic tool. Interest in vasopressin has been renewed with the availability of vaptans, new, potent, orally active vasopressin receptor antagonists, initially developed for the treatment of various forms of hyponatremia (often related to vasopressin dysfunction) and proven to be safe in humans [109-111]. Evaluation of the specific aquaretic effect of vaptans in aged patients treated with this antagonist might have a profound impact in understanding the therapeutic effect of vaptan compounds.

Interestingly, vasopressin, the levels of which are increased after water deprivation, stimulates vascular superoxide production through activation of V1aR [112]. Accordingly, it has been shown that water deprivation increases ROS production in the somatosensory cortex, indicating that cerebrovascular dysfunction is related to oxidative stress [113].

5.1. Oxidative Signals and AQP2. Oxidative stress plays a key role in modulating renal functionality, including its diluting and concentrating ability during aging [114]. Oxidative stress increases the risk of developing several age-related diseases because ROS may alter cell signaling, leading to inflammation, apoptosis, and cellular senescence. During aging, significant increases in advanced glycosylation end products (AGE) and other oxidants have been reported in kidneys $[115,116]$. Chronic inhibition of nitric oxidase synthase regulates renal water balance by reducing the expression of AQP2 [117, 118]. Importantly, oxidative stress is often associated with disorders linked to redox unbalance.

At a molecular level, ROS can oxidize selective amino acids on target proteins. Oxidative dependent modifications are being shown to be fundamental in transducing several intracellular signals controlling pleiotropic functions such as cell proliferation, apoptosis, autophagy, and membrane transport. These modifications result from reactions between ROS or reactive nitrogen species (RNS) and amino acid residues [26]. Oxidative modifications mainly occur through the switching of the sulfur in target cysteines. However, cysteines are not the only residues involved in oxidative modifications as methionine, lysine, arginine, threonine, and proline residues can also be oxidized to reactive carbonyls [119]. Oxidative sensitive modifications include carbonylation, nitrotyrosinylation, succinylation, S-sulfenation, S-nitrosylation, S-glutathionylation, and disulfide formation.

Reversible glutathionylation results from the reaction between glutathione and cysteine residues (PSSG) upon exposure to RS. S-Glutathionylation is recognized as a crucial modification by which cells translate local changes of reactive species [120].

Using a proteomic approach, Sandoval and coworkers revealed that vasopressin stimulation is associated with increased expression of different oxidative related proteins such as glutathione S-transferase [121]. This observation is likely to indicate that oxidative signaling may somehow play a role in controlling the physiological signal transduction cascade initiated by vasopressin. Studies from several groups have revealed, indeed, that antioxidant compounds such as $\mathrm{N}$-acetylcysteine (NAC) rescued the reduction of AQP2 abundance observed in rats subjected to the bilateral ureteral obstruction (BUO) [122]. Conversely, treatment with the oxidant 4-hydroxy-2-hexenal (HHE) decreases the abundance of AQP2 and activates several kinases such as p38MAPK and ERK [123], which have been proposed to phosphorylate AQP2 at S261 [124-126]. Phosphorylation at S261 is involved in AQP2 ubiquitylation and degradation $[125,127]$.

However, vasopressin is not the only factor regulating AQP2 expression. In this respect, it has been demonstrated that the oxidant HHE increases the expression of the transcription factors NF- $\kappa \mathrm{B}$ and the enzyme NOX4 [123], both involved in modulating the expression level of AQP2. Specifically, NF- $\kappa \mathrm{B}$ decreased $A Q P 2$ mRNA and protein abundance [128]. Conversely, NOX4 promotes $A Q P 2$ expression [129]. These findings strongly suggest that AQP2 abundance is the result of a balanced activity between NF- $\kappa$ B and NOX4. However, how oxidative signals modulate the stability of the target proteins remains to be clarified. It appears conceivable that transient oxidative posttranslational modifications may mean there is a molecular signature translating oxidative information signaling and thus controlling the fate of target proteins. In this respect, some of the authors of this review have recently shown that AQP2 undergoes Sglutathionylation. It was also found that the increase in AQP2 glutathionylation is paralleled by higher ROS production. Conversely, low levels of ROS, measured in cells displaying low intracellular calcium concentration, secondary to the expression of the calcium-sensing receptor (CaSR), associates with reduced S-glutathionylation of AQP2 [130]. Whether or not S-glutathionylation of AQP2 is involved in the water imbalance observed during aging remains to be investigated.

\section{Modulatory Actions of Food Antioxidant Phytocompounds on Aquaporins}

A growing number of food phytochemicals are being found to exert antioxidant and anti-inflammatory actions. Thanks to their ability to interact with pivotal signaling pathways, a number of food and herbal phytochemicals have been found to impart health benefits modulating important cellular functions such as growth, differentiation, death, and volume homeostasis as well as redox, metabolic, and energy balance.

To date, a large number of biologically active phytochemicals have been identified, characterized, and eventually modified as natural sources of novel compounds to prevent, delay, or cure many human diseases. This is an important 
achievement since secondary prevention or adjunct therapy through dietary intervention is a cost-effective alternative for avoiding the large burden of health care, especially that associated with chronic illnesses.

Similarly to several other transport systems, AQPs are also modulated by a number of food bioactive phytocompounds $[131,132]$. The modulatory effects exerted by beneficial dietary patterns, food phytochemicals, and herbal compounds on AQPs, in both health and disease, is a fast growing topic as their exploitation may help support current medical treatment options to improve the prognosis of several diseases. Flavonoid modulation of AQPs has been reported to ameliorate forms of cerebral and retinal edemas of different origins (AQP4) [132-135], lung injuries (AQP1) [136], and Sjögren syndrome-associated xerostomia (AQP5) [137], to inhibit ovarian tumor growth (AQP5) [89] and protect against UV-induced skin damage (AQP3) [63]. Curcumin influences choroid plexus AQP1 [138], ovarian AQP3 [139], and brain AQP4 and AQP9, reducing intracranial pressure in brain injury, inhibiting ovarian cancer cell migration, and reducing brain edema, respectively [140142]. Modulation of AQP channel gating by curcumin has been recently reported in a paper describing the use of $\mathrm{HeLa}$ cells to investigate the effects of some antioxidant phytocompounds on AQP1, AQP3, AQP8, and AQP11 [60]. Resveratrol, a stilbene compound, was found to inhibit human keratinocytes and ameliorate the ischemia/reperfusion injury acting on AQP3 [64] and AQP4 [143], respectively. The chalcone compound phloretin also acts on the expression of AQP9 to exert its antioxidant and anti-inflammatory actions [144]. Genistein and daidzein, two isoflavonoids, were found to upregulate the expression of uterine AQP1 by increasing the responsiveness to estrogens [145]. The monoterpenoid carvacrol has been reported to reduce the intracerebral hemorrhage-induced brain edema by downregulating brain AQP4 [146]. Triterpenoids have been shown to act on the expression of AQP1 to reduce cancer cell migration, counteracting metastasis, as well as to ameliorate forms of allergic rhinitis and to downregulate kidney AQP2 to protect against renal failures [147]. Capsaicin was found to increase the expression level of submandibular salivary gland AQP5 to ameliorate salivary gland hypofunction [148, 149]. While useful information is already available, further important achievements are expected from the ongoing studies on the modulatory effects exerted by biologically active phytocompounds on the expression and function of AQPs.

\section{Conclusions and Future Perspectives}

Excess of ROS within the cells and reduction of NO bioavailability can largely promote cellular dysfunction, which is linked to the development of metabolic disorders, cardiovascular and renal diseases, frailty, and aging. Key roles for AQPs as peroxiporins in the signal transduction pathways underlying diverse cellular functions, such as differentiation, proliferation, or mobility, are suggested by the recent evidence of AQP-mediated $\mathrm{H}_{2} \mathrm{O}_{2}$ transport at the plasma or mitochondrial membrane level. Dysregulation of peroxiporin function can lead to oxidative stress and eventually cell death.
Alterations in AQP-mediated ROS and/or NO transport are therefore assuming an increasing translational value in physiology and pathophysiology with promising nutraceutical and pharmacological implications. Indeed, modulation of the peroxiporin and/or NO channel function of AQPs at the vascular, hepatic, testicular, or renal level may prove to be valuable in preventing or treating cardiovascular (vascular stiffness/hypertension, atherosclerosis), metabolic, and reproductive (impaired sperm cell motility) diseases. Last but not least, further work is warranted to investigate the involvement of AQPs in the antioxidant and antiinflammatory actions exerted by food phytochemical compounds in order to devise new strategies to promote health and improve aging.

\section{Conflicts of Interest}

The authors declare they do not have any conflicts of interest.

\section{Acknowledgments}

Grazia Tamma and Giuseppe Calamita acknowledge the financial contribution from Fondazione Cariplo and Daniel \& Nina Carasso Foundation (project LeGeReTe \#1507-200 AF, \#FC 2015-2440, and \#FDNC Engt 00063479 supported under the "Thought for Food" Initiative of Agropolis Foundation through the "Investissements d'avenir" programme with reference number ANR-10-LABX-0001-01).

\section{References}

[1] M. P. Murphy, "How mitochondria produce reactive oxygen species," The Biochemical Journal, vol. 417, no. 1, pp. 1-13, 2009.

[2] D. B. Zorov, M. Juhaszova, and S. J. Sollott, "Mitochondrial reactive oxygen species (ROS) and ROS-induced ROS release," Physiological Reviews, vol. 94, no. 3, pp. 909-950, 2014

[3] B. Uttara, A. Singh, P. Zamboni, and R. Mahajan, "Oxidative stress and neurodegenerative diseases: a review of upstream and downstream antioxidant therapeutic options," Current Neuropharmacology, vol. 7, no. 1, pp. 65-74, 2009.

[4] L. Zuo, T. Zhou, B. K. Pannell, A. C. Ziegler, and T. M. Best, "Biological and physiological role of reactive oxygen species-the good, the bad and the ugly," Acta Physiologica, vol. 214, no. 3, pp. 329-348, 2015.

[5] M. de la Paz Scribano, M. del Carmen Baez, B. Florencia et al., "Effects of atorvastatin on oxidative stress biomarkers and mitochondrial morphofunctionality in hyperfibrinogenemiainduced atherogenesis," Advances in Medicine, vol. 2014, Article ID 947258, 6 pages, 2014.

[6] P. Ferroni, S. Basili, V. Paoletti, and G. Davi, "Endothelial dysfunction and oxidative stress in arterial hypertension," Nutrition, Metabolism, and Cardiovascular Diseases, vol. 16, no. 3, pp. 222-233, 2006.

[7] J. Vasquez-Vivar, B. Kalyanaraman, P. Martasek et al., "Superoxide generation by endothelial nitric oxide synthase: the influence of cofactors," Proceedings of the National Academy of Sciences of the United States of America, vol. 95, no. 16, pp. 9220-9225, 1998. 
[8] N. Panth, K. R. Paudel, and K. Parajuli, "Reactive oxygen species: a key hallmark of cardiovascular disease," Advances in Medicine, vol. 2016, Article ID 9152732, 12 pages, 2016.

[9] V. Bauer and R. Sotnikova, "Nitric oxide-the endotheliumderived relaxing factor and its role in endothelial functions," General Physiology and Biophysics, vol. 29, no. 4, pp. 319340, 2010.

[10] G. P. Bienert, A. L. B. Møller, K. A. Kristiansen et al., "Specific aquaporins facilitate the diffusion of hydrogen peroxide across membranes," The Journal of Biological Chemistry, vol. 282, no. 2, pp. 1183-1192, 2007.

[11] M. Herrera, N. J. Hong, and J. L. Garvin, "Aquaporin-1 transports NO across cell membranes," Hypertension, vol. 48, no. 1, pp. 157-164, 2006.

[12] L. A. Pham-Huy, H. He, and C. Pham-Huy, "Free radicals, antioxidants in disease and health," International Journal of Biomedical Sciences, vol. 4, no. 2, pp. 89-96, 2008.

[13] I. Grattagliano, G. Calamita, T. Cocco, D. Q. Wang, and P. Portincasa, "Pathogenic role of oxidative and nitrosative stress in primary biliary cirrhosis," World Journal of Gastroenterology, vol. 20, no. 19, pp. 5746-5759, 2014.

[14] K. Bedard, B. Lardy, and K. Krause, "NOX family NADPH oxidases: not just in mammals," Biochimie, vol. 89, no. 9, pp. 1107-1112, 2007.

[15] W. Droge, "Free radicals in the physiological control of cell function," Physiological Reviews, vol. 82, no. 1, pp. 47-95, 2002.

[16] M. Genestra, "Oxyl radicals, redox-sensitive signalling cascades and antioxidants," Cellular Signalling, vol. 19, no. 9, pp. 1807-1819, 2007.

[17] P. Pacher, J. S. Beckman, and L. Liaudet, "Nitric oxide and peroxynitrite in health and disease," Physiological Reviews, vol. 87, no. 1, pp. 315-424, 2007.

[18] J. F. Turrens, "Mitochondrial formation of reactive oxygen species," The Journal of Physiology, vol. 552, no. 2, pp. 335344, 2003.

[19] C. Maack and M. Bohm, "Targeting mitochondrial oxidative stress in heart failure throttling the afterburner," Journal of the American College of Cardiology, vol. 58, no. 1, pp. 8386, 2011.

[20] C. Betlazar, R. J. Middleton, R. B. Banati, and G. J. Liu, “The impact of high and low dose ionising radiation on the central nervous system," Redox Biology, vol. 9, pp. 144-156, 2016.

[21] P. Agre, "Aquaporin water channels," Bioscience Reports, vol. 24, no. 3, pp. 127-163, 2004.

[22] P. Gena, M. Pellegrini-Calace, A. Biasco, M. Svelto, and G. Calamita, "Aquaporin membrane channels: biophysics, classification, functions, and possible biotechnological applications," Food biophysics, vol. 6, no. 2, pp. 241-249, 2011.

[23] K. Ishibashi, "New members of mammalian aquaporins: AQP10-AQP12," Handbook of Experimental Pharmacology, vol. 190, pp. 251-262, 2009.

[24] T. P. Jahn, A. L. B. Møller, T. Zeuthen et al., "Aquaporin homologues in plants and mammals transport ammonia," FEBS Letters, vol. 574, no. 1-3, pp. 31-36, 2004.

[25] A. Almasalmeh, D. Krenc, B. Wu, and E. Beitz, "Structural determinants of the hydrogen peroxide permeability of aquaporins," The FEBS Journal, vol. 281, no. 3, pp. 647-656, 2014.

[26] G. Tamma and G. Valenti, "Evaluating the oxidative stress in renal diseases: what is the role for S-glutathionylation?," Antioxidants \& Redox Signaling, vol. 25, no. 3, pp. 147-164, 2016.
[27] L. M. Holm, T. P. Jahn, A. L. B. Møller et al., " $\mathrm{NH}_{3}$ and $\mathrm{NH}_{4}{ }^{+}$ permeability in aquaporin-expressing Xenopus oocytes," Pflugers Archiv: European Journal of Physiology, vol. 450, no. 6, pp. 415-428, 2005.

[28] S. M. Saparov, K. Liu, P. Agre, and P. Pohl, "Fast and selective ammonia transport by aquaporin-8," The Journal of Biological Chemistry, vol. 282, no. 8, pp. 5296-5301, 2007.

[29] B. Wu and E. Beitz, "Aquaporins with selectivity for unconventional permeants," Cellular and Molecular Life Sciences, vol. 64, no. 18, pp. 2413-2421, 2007.

[30] N. L. Nakhoul, B. A. Davis, M. F. Romero, and W. F. Boron, "Effect of expressing the water channel aquaporin-1 on the $\mathrm{CO}_{2}$ permeability of Xenopus oocytes," American Journal of Physiology-Cell Physiology, vol. 274, no. 2, pp. C543-C548, 1998.

[31] Y. Wang, J. Cohen, W. F. Boron, K. Schulten, and E. Tajkhorshid, "Exploring gas permeability of cellular membranes and membrane channels with molecular dynamics," Journal of Structural Biology, vol. 157, no. 3, pp. 534-544, 2007.

[32] W. F. Boron, "Sharpey-Schafer lecture: gas channels," Experimental Physiology, vol. 95, no. 12, pp. 1107-1130, 2010.

[33] G. Calamita, C. Delporte, and R. A. Marinelli, Hepatobiliary, Salivary Glands and Pancreatic Aquaporins in Health and Disease, 2015, Place Published.

[34] A. Boveris and E. Cadenas, "Mitochondrial production of hydrogen peroxide regulation by nitric oxide and the role of ubisemiquinone," IUBMB Life, vol. 50, no. 4, pp. 245-250, 2000.

[35] H. Sies, "Role of metabolic $\mathrm{H}_{2} \mathrm{O}_{2}$ generation: redox signaling and oxidative stress," The Journal of Biological Chemistry, vol. 289, no. 13, pp. 8735-8741, 2014.

[36] T. Finkel, "Signal transduction by mitochondrial oxidants," The Journal of Biological Chemistry, vol. 287, no. 7, pp. 4434-4440, 2012.

[37] R. Solito, F. Corti, C. H. Chen et al., "Mitochondrial aldehyde dehydrogenase-2 activation prevents $\beta$-amyloid-induced endothelial cell dysfunction and restores angiogenesis," Journal of Cell Science, vol. 126, no. 9, pp. 1952-1961, 2013.

[38] F. Yin, H. Sancheti, and E. Cadenas, "Mitochondrial thiols in the regulation of cell death pathways," Antioxidants \& Redox Signaling, vol. 17, no. 12, pp. 1714-1727, 2012.

[39] F. Antunes and E. Cadenas, "Estimation of $\mathrm{H}_{2} \mathrm{O}_{2}$ gradients across biomembranes," FEBS Letters, vol. 475, no. 2, pp. 121-126, 2000.

[40] G. P. Bienert and F. Chaumont, "Aquaporin-facilitated transmembrane diffusion of hydrogen peroxide," Biochimica et Biophysica Acta (BBA) - General Subjects, vol. 1840, no. 5, pp. 1596-1604, 2014.

[41] N. Makino, K. Sasaki, K. Hashida, and Y. Sakakura, "A metabolic model describing the $\mathrm{H}_{2} \mathrm{O}_{2}$ elimination by mammalian cells including $\mathrm{H}_{2} \mathrm{O}_{2}$ permeation through cytoplasmic and peroxisomal membranes: comparison with experimental data," Biochimica et Biophysica Acta (BBA) - General Subjects, vol. 1673, no. 3, pp. 149-159, 2004.

[42] V. G. Grivennikova, A. V. Kareyeva, and A. D. Vinogradov, "What are the sources of hydrogen peroxide production by heart mitochondria?," Biochimica et Biophysica Acta (BBA) Bioenergetics, vol. 1797, no. 6-7, pp. 939-944, 2010.

[43] E. W. Miller, B. C. Dickinson, and C. J. Chang, "Aquaporin-3 mediates hydrogen peroxide uptake to regulate downstream 
intracellular signaling," Proceedings of the National Academy of Sciences of the United States of America, vol. 107, no. 36, pp. 15681-15686, 2010.

[44] M. Bertolotti, S. Bestetti, J. M. Garcia-Manteiga et al., "Tyrosine kinase signal modulation: a matter of $\mathrm{H}_{2} \mathrm{O}_{2}$ membrane permeability?," Antioxidants \& Redox Signaling, vol. 19, no. 13, pp. 1447-1451, 2013.

[45] M. Bertolotti, G. Farinelli, M. Galli, A. Aiuti, and R. Sitia, "AQP8 transports NOX2-generated $\mathrm{H}_{2} \mathrm{O}_{2}$ across the plasma membrane to promote signaling in B cells," Journal of Leukocyte Biology, vol. 100, no. 5, pp. 1071-1079, 2016.

[46] F. Vieceli Dalla Sega, C. Prata, L. Zambonin et al., "Intracellular cysteine oxidation is modulated by aquaporin-8-mediated hydrogen peroxide channeling in leukaemia cells," BioFactors, vol. 43, no. 2, pp. 232-242, 2017.

[47] F. Vieceli Dalla Sega, L. Zambonin, D. Fiorentini et al., "Specific aquaporins facilitate Nox-produced hydrogen peroxide transport through plasma membrane in leukaemia cells," Biochimica et Biophysica Acta (BBA) - Molecular Cell Research, vol. 1843, no. 4, pp. 806-814, 2014.

[48] R. A. Marinelli, G. L. Lehmann, L. R. Soria, and M. J. Marchissio, "Hepatocyte aquaporins in bile formation and cholestasis," Frontiers in Bioscience, vol. 16, no. 1, p. 2642, 2011.

[49] D. Ferri, A. Mazzone, G. E. Liquori, G. Cassano, M. Svelto, and G. Calamita, "Ontogeny, distribution, and possible functional implications of an unusual aquaporin, AQP8, in mouse liver," Hepatology, vol. 38, no. 4, pp. 947-957, 2003.

[50] G. Calamita, D. Ferri, P. Gena et al., "The inner mitochondrial membrane has aquaporin-8 water channels and is highly permeable to water," The Journal of Biological Chemistry, vol. 280, no. 17, pp. 17149-17153, 2005.

[51] M. J. Marchissio, D. E. A. Francés, C. E. Carnovale, and R. A. Marinelli, "Mitochondrial aquaporin-8 knockdown in human hepatoma HepG2 cells causes ROS-induced mitochondrial depolarization and loss of viability," Toxicology and Applied Pharmacology, vol. 264, no. 2, pp. 246-254, 2012.

[52] F. Chauvigne, M. Boj, R. N. Finn, and J. Cerda, "Mitochondrial aquaporin-8-mediated hydrogen peroxide transport is essential for teleost spermatozoon motility," Scientific Reports, vol. 5, no. 1, p. 7789, 2015.

[53] U. Laforenza, G. Pellavio, A. Marchetti, C. Omes, F. Todaro, and G. Gastaldi, "Aquaporin-mediated water and hydrogen peroxide transport is involved in normal human spermatozoa functioning," International Journal of Molecular Sciences, vol. 18, no. 12, 2017.

[54] M. J. Marchissio, D. E. A. Francés, C. E. Carnovale, and R. A. Marinelli, "Evidence for necrosis, but not apoptosis, in human hepatoma cells with knockdown of mitochondrial aquaporin-8," Apoptosis, vol. 19, no. 5, pp. 851-859, 2014.

[55] I. Medrano-Fernandez, S. Bestetti, M. Bertolotti et al., "Stress regulates aquaporin-8 permeability to impact cell growth and survival," Antioxidants \& Redox Signaling, vol. 24, no. 18, pp. 1031-1044, 2016.

[56] R. A. Marinelli and M. J. Marchissio, "Mitochondrial aquaporin-8: a functional peroxiporin?," Antioxidants \& Redox Signaling, vol. 19, no. 8, p. 896, 2013.

[57] M. Danielli, A. M. Capiglioni, J. Marrone, G. Calamita, and R. A. Marinelli, "Cholesterol can modulate mitochondrial aquaporin-8 expression in human hepatic cells," IUBMB Life, vol. 69 , no. 5, pp. 341-346, 2017.
[58] A. M. Giudetti, F. Damiano, G. V. Gnoni, and L. Siculella, "Low level of hydrogen peroxide induces lipid synthesis in BRL-3A cells through a CAP-independent SREBP-1a activation," The International Journal of Biochemistry \& Cell Biology, vol. 45, no. 7, pp. 1419-1426, 2013.

[59] M. Boj, F. Chauvigne, and J. Cerda, "Coordinated action of aquaporins regulates sperm motility in a marine teleost," Biology of Reproduction, vol. 93, no. 2, p. 40, 2015.

[60] G. Pellavio, M. Rui, L. Caliogna et al., "Regulation of aquaporin functional properties mediated by the antioxidant effects of natural compounds," International Journal of Molecular Sciences, vol. 18, no. 12, 2017.

[61] M. Hara-Chikuma, S. Chikuma, Y. Sugiyama et al., "Chemokine-dependent $\mathrm{T}$ cell migration requires aquaporin-3mediated hydrogen peroxide uptake," The Journal of Experimental Medicine, vol. 209, no. 10, pp. 1743-1752, 2012.

[62] M. Hara-Chikuma, H. Satooka, S. Watanabe et al., "Aquaporin-3-mediated hydrogen peroxide transport is required for $\mathrm{NF}-\kappa \mathrm{B}$ signalling in keratinocytes and development of psoriasis," Nature Communications, vol. 6, no. 1, p. 7454, 2015.

[63] N. L. Wu, J. Y. Fang, M. Chen, C. J. Wu, C. C. Huang, and C. F. Hung, "Chrysin protects epidermal keratinocytes from UVA- and UVB-induced damage," Journal of Agricultural and Food Chemistry, vol. 59, no. 15, pp. 8391-8400, 2011.

[64] Z. Wu, H. Uchi, S. Morino-Koga, W. Shi, and M. Furue, "Resveratrol inhibition of human keratinocyte proliferation via SIRT1/ARNT/ERK dependent downregulation of aquaporin 3," Journal of Dermatological Science, vol. 75, no. 1, pp. 1623, 2014.

[65] H. Xie, F. Liu, L. Liu et al., "Protective role of AQP3 in UVAinduced NHSFs apoptosis via Bcl2 up-regulation," Archives of Dermatological Research, vol. 305, no. 5, pp. 397-406, 2013.

[66] I. Seleit, O. A. Bakry, H. S. El Rebey, G. El-Akabawy, and G. Hamza, "Is Aquaporin-3 a determinant factor of intrinsic and extrinsic aging? An immunohistochemical and morphometric study," Applied Immunohistochemistry \& Molecular Morphology, vol. 25, no. 1, pp. 49-57, 2017.

[67] J. R. Thiagarajah, D. Zhao, and A. S. Verkman, "Impaired enterocyte proliferation in aquaporin-3 deficiency in mouse models of colitis," Gut, vol. 56, no. 11, pp. 1529-1535, 2007.

[68] J. R. Thiagarajah, J. Chang, J. A. Goettel, A. S. Verkman, and W. I. Lencer, "Aquaporin-3 mediates hydrogen peroxidedependent responses to environmental stress in colonic epithelia," Proceedings of the National Academy of Sciences of the United States of America, vol. 114, no. 3, pp. 568-573, 2017.

[69] M. Hara-Chikuma, S. Watanabe, and H. Satooka, "Involvement of aquaporin-3 in epidermal growth factor receptor signaling via hydrogen peroxide transport in cancer cells," Biochemical and Biophysical Research Communications, vol. 471, no. 4, pp. 603-609, 2016.

[70] P. Ricanek, L. K. Lunde, S. A. Frye et al., "Reduced expression of aquaporins in human intestinal mucosa in early stage inflammatory bowel disease," Clinical and Experimental Gastroenterology, vol. 8, pp. 49-67, 2015.

[71] H. Satooka and M. Hara-Chikuma, "Aquaporin-3 controls breast cancer cell migration by regulating hydrogen peroxide transport and its downstream cell signaling," Molecular and Cellular Biology, vol. 36, no. 7, pp. 1206-1218, 2016.

[72] T. Marchbank and R. J. Playford, "Trefoil factor family peptides enhance cell migration by increasing cellular osmotic 
permeability and aquaporin 3 levels," The FASEB Journal, vol. 32, no. 2, pp. 1017-1024, 2018.

[73] K. Asai, R. K. Kudej, Y. T. Shen et al., "Peripheral vascular endothelial dysfunction and apoptosis in old monkeys," Arteriosclerosis, Thrombosis, and Vascular Biology, vol. 20, no. 6, pp. 1493-1499, 2000.

[74] D. S. Celermajer, K. E. Sorensen, D. J. Spiegelhalter, D. Georgakopoulos, J. Robinson, and J. E. Deanfield, “Aging is associated with endothelial dysfunction in healthy men years before the age-related decline in women," Journal of the American College of Cardiology, vol. 24, no. 2, pp. 471476, 1994.

[75] Q. Shi, K. Aida, J. L. Vandeberg, and X. L. Wang, "Passagedependent changes in baboon endothelial cells-relevance to in vitro aging," DNA and Cell Biology, vol. 23, no. 8, pp. 502-509, 2004.

[76] M. Wang, J. Zhang, L. Q. Jiang et al., "Proinflammatory profile within the grossly normal aged human aortic wall," Hypertension, vol. 50, no. 1, pp. 219-227, 2007.

[77] L. J. Ignarro, G. M. Buga, K. S. Wood, R. E. Byrns, and G. Chaudhuri, "Endothelium-derived relaxing factor produced and released from artery and vein is nitric oxide," Proceedings of the National Academy of Sciences of the United States of America, vol. 84, no. 24, pp. 9265-9269, 1987.

[78] F. Paneni, C. Diaz Canestro, P. Libby, T. F. Luscher, and G. G. Camici, "The aging cardiovascular system: understanding it at the cellular and clinical levels," Journal of the American College of Cardiology, vol. 69, no. 15, pp. 1952-1967, 2017.

[79] M. A. Potenza, F. Addabbo, and M. Montagnani, "Vascular actions of insulin with implications for endothelial dysfunction," American Journal of Physiology Endocrinology and Metabolism, vol. 297, no. 3, pp. E568-E577, 2009.

[80] L. J. Ignarro and C. Napoli, "Novel features of nitric oxide, endothelial nitric oxide synthase, and atherosclerosis," Current Atherosclerosis Reports, vol. 6, no. 4, pp. 281-287, 2004.

[81] S. Taddei, A. Virdis, L. Ghiadoni et al., "Age-related reduction of NO availability and oxidative stress in humans," Hypertension, vol. 38, no. 2, pp. 274-279, 2001.

[82] A. L. Sverdlov, W. P. A. Chan, N. E. K. Procter, Y. Y. Chirkov, D. T. M. Ngo, and J. D. Horowitz, "Reciprocal regulation of NO signaling and TXNIP expression in humans: impact of aging and ramipril therapy," International Journal of Cardiology, vol. 168, no. 5, pp. 4624-4630, 2013.

[83] R. M. J. Palmer, A. G. Ferrige, and S. Moncada, "Nitric oxide release accounts for the biological activity of endotheliumderived relaxing factor," Nature, vol. 327, no. 6122, pp. 524-526, 1987.

[84] S. Donnini, M. Monti, R. Roncone et al., "Peroxynitrite inactivates human-tissue inhibitor of metalloproteinase-4," FEBS Letters, vol. 582, no. 7, pp. 1135-1140, 2008.

[85] M. A. Incalza, R. D'Oria, A. Natalicchio, S. Perrini, L. Laviola, and F. Giorgino, "Oxidative stress and reactive oxygen species in endothelial dysfunction associated with cardiovascular and metabolic diseases," Vascular Pharmacology, vol. 100, pp. 1-19, 2018.

[86] M. Monti, S. Donnini, A. Giachetti, D. Mochly-Rosen, and M. Ziche, " $\delta \mathrm{PKC}$ inhibition or varepsilonPKC activation repairs endothelial vascular dysfunction by regulating eNOS post-translational modification," Journal of Molecular and Cellular Cardiology, vol. 48, no. 4, pp. 746-756, 2010.
[87] U. Forstermann and H. Li, "Therapeutic effect of enhancing endothelial nitric oxide synthase (eNOS) expression and preventing eNOS uncoupling," British Journal of Pharmacology, vol. 164, no. 2, pp. 213-223, 2011.

[88] D.-D. Chen, L.-Y. Chen, J.-B. Xie et al., "Tetrahydrobiopterin regulation of eNOS redox function," Current Pharmaceutical Design, vol. 20, no. 22, pp. 3554-3562, 2014.

[89] Y. M. Yang, A. Huang, G. Kaley, and D. Sun, "eNOS uncoupling and endothelial dysfunction in aged vessels," American Journal of Physiology Heart and Circulatory Physiology, vol. 297, no. 5, pp. H1829-H1836, 2009.

[90] T. Malinski, Z. Taha, S. Grunfeld, S. Patton, M. Kapturczak, and P. Tomboulian, "Diffusion of nitric oxide in the aorta wall monitored in situ by porphyrinic microsensors," Biochemical and Biophysical Research Communications, vol. 193, no. 3, pp. 1076-1082, 1993.

[91] M. Moller, H. Botti, C. Batthyany, H. Rubbo, R. Radi, and A. Denicola, "Direct measurement of nitric oxide and oxygen partitioning into liposomes and low density lipoprotein," The Journal of Biological Chemistry, vol. 280, no. 10, pp. 88508854, 2005.

[92] M. Herrera and J. L. Garvin, "Novel role of AQP-1 in NOdependent vasorelaxation," American Journal of Physiology Renal Physiology, vol. 292, no. 5, pp. F1443-F1451, 2007.

[93] J. U. Lee, Y. W. Oh, and S. W. Kim, “Altered renal expression of aquaporin-2 water channels in rats with experimental twokidney, one clip hypertension," Journal of Korean Medical Science, vol. 16, no. 4, pp. 462-466, 2001.

[94] V. Montiel, E. Leon Gomez, C. Bouzin et al., "Genetic deletion of aquaporin-1 results in microcardia and low blood pressure in mouse with intact nitric oxide-dependent relaxation, but enhanced prostanoids-dependent relaxation," Pflugers Archiv: European Journal of Physiology, vol. 466, no. 2, pp. 237-251, 2014.

[95] R. D. Fontijn, O. L. Volger, T. C. van der Pouw-Kraan et al., "Expression of nitric oxide-transporting aquaporin1 is controlled by KLF2 and marks non-activated endothelium in vivo," PLoS One, vol. 10, no. 12, article e0145777, 2015.

[96] W. L. Kenney and P. Chiu, "Influence of age on thirst and fluid intake," Medicine and Science in Sports and Exercise, vol. 33, no. 9, pp. 1524-1532, 2001.

[97] J. A. Suhr, J. Hall, S. M. Patterson, and R. T. Niinisto, “The relation of hydration status to cognitive performance in healthy older adults," International Journal of Psychophysiology, vol. 53, no. 2, pp. 121-125, 2004.

[98] J. A. Suhr, S. M. Patterson, A. W. Austin, and K. L. Heffner, "The relation of hydration status to declarative memory and working memory in older adults," The Journal of Nutrition, Health \& Aging, vol. 14, no. 10, pp. 840-843, 2010.

[99] P. Voyer, S. Richard, L. Doucet, and P. H. Carmichael, "Predisposing factors associated with delirium among demented long-term care residents," Clinical Nursing Research, vol. 18, no. 2, pp. 153-171, 2009.

[100] L. Nadav, A. Y. Gur, A. D. Korczyn, and N. M. Bornstein, "Stroke in hospitalized patients: are there special risk factors?," Cerebrovascular Diseases, vol. 13, no. 2, pp. 127-131, 2002.

[101] G. J. Rodriguez, S. M. Cordina, G. Vazquez et al., “The hydration influence on the risk of stroke (THIRST) study," Neurocritical Care, vol. 10, no. 2, pp. 187-194, 2009. 
[102] L. E. Cowen, S. P. Hodak, and J. G. Verbalis, "Age-associated abnormalities of water homeostasis," Endocrinology and Metabolism Clinics of North America, vol. 42, no. 2, pp. 349-370, 2013.

[103] G. Tamma, N. Goswami, J. Reichmuth, N. G. De Santo, and G. Valenti, "Aquaporins, vasopressin, and aging: current perspectives,” Endocrinology, vol. 156, no. 3, pp. 777-788, 2015.

[104] J. M. Sands, "Urine concentrating and diluting ability during aging," The Journals of Gerontology. Series A, Biological Sciences and Medical Sciences, vol. 67, no. 12, pp. 1352-1357, 2012.

[105] S. Combet, S. Gouraud, R. Gobin et al., "Aquaporin-2 downregulation in kidney medulla of aging rats is posttranscriptional and is abolished by water deprivation," American Journal of Physiology Renal Physiology, vol. 294, no. 6, pp. F1408-F1414, 2008.

[106] T. Katsura, C. E. Gustafson, D. A. Ausiello, and D. Brown, "Protein kinase A phosphorylation is involved in regulated exocytosis of aquaporin-2 in transfected LLC-PK1 cells," The American Journal of Physiology, vol. 272, no. 6, Part 2, pp. F817-F822, 1997.

[107] J. D. Hoffert, T. Pisitkun, G. Wang, R. F. Shen, and M. A. Knepper, "Quantitative phosphoproteomics of vasopressinsensitive renal cells: regulation of aquaporin-2 phosphorylation at two sites," Proceedings of the National Academy of Sciences of the United States of America, vol. 103, no. 18, pp. 7159-7164, 2006.

[108] S. Combet, L. Teillet, G. Geelen et al., "Food restriction prevents age-related polyuria by vasopressin-dependent recruitment of aquaporin-2," American Journal of Physiology Renal Physiology, vol. 281, no. 6, pp. F1123-F1131, 2001.

[109] T. Berl, F. Quittnat-Pelletier, J. G. Verbalis et al., "Oral tolvaptan is safe and effective in chronic hyponatremia," Journal of the American Society of Nephrology, vol. 21, no. 4, pp. 705-712, 2010.

[110] O. Devuyst and V. E. Torres, "Osmoregulation, vasopressin, and cAMP signaling in autosomal dominant polycystic kidney disease," Current Opinion in Nephrology and Hypertension, vol. 22, no. 4, pp. 459-470, 2013.

[111] R. W. Schrier, P. Gross, M. Gheorghiade et al., “Tolvaptan, a selective oral vasopressin V2-receptor antagonist, for hyponatremia," The New England Journal of Medicine, vol. 355, no. 20, pp. 2099-2112, 2006.

[112] L. Li, J. J. Galligan, G. D. Fink, and A. F. Chen, "Vasopressin induces vascular superoxide via endothelin-1 in mineralocorticoid hypertension," Hypertension, vol. 41, no. 3, pp. 663-668, 2003.

[113] G. Faraco, T. S. Wijasa, L. Park, J. Moore, J. Anrather, and C. Iadecola, "Water deprivation induces neurovascular and cognitive dysfunction through vasopressin-induced oxidative stress," Journal of Cerebral Blood Flow and Metabolism, vol. 34, no. 5, pp. 852-860, 2014.

[114] V. M. Mendoza-Nunez, M. Ruiz-Ramos, M. A. SanchezRodriguez, R. Retana-Ugalde, and J. L. Munoz-Sanchez, "Aging-related oxidative stress in healthy humans," The Tohoku Journal of Experimental Medicine, vol. 213, no. 3, pp. 261-268, 2007.

[115] R. Bucala, "Diabetes, aging, and their tissue complications," The Journal of Clinical Investigation, vol. 124, no. 5, pp. 1887-1888, 2014.
[116] J. F. Reckelhoff, V. Kanji, L. C. Racusen et al., "Vitamin E ameliorates enhanced renal lipid peroxidation and accumulation of F2-isoprostanes in aging kidneys," American Journal of Physiology-Regulatory, Integrative and Comparative Physiology, vol. 274, no. 3, pp. R767-R774, 1998.

[117] M. F. Albertoni Borghese, M. P. Majowicz, M. C. Ortiz, M. F. Delgado, N. B. Sterin Speziale, and N. A. Vidal, "Renal sodium-glucose cotransporter activity and aquaporin-2 expression in rat kidney during chronic nitric oxide synthase inhibition," Nephron Physiology, vol. 107, no. 3, pp. p77-p86, 2007.

[118] N. Arreche, A. Fellet, M. Lopez, J. Lopez-Costa, C. Arranz, and A. M. Balaszczuk, "Hypovolemic state: involvement of nitric oxide in the aged related alterations of aquaporins-2 abundance in rat kidney," Vascular Pharmacology, vol. 49, no. 1, pp. 19-25, 2008.

[119] R. C. Bollineni, R. Hoffmann, and M. Fedorova, "Proteomewide profiling of carbonylated proteins and carbonylation sites in HeLa cells under mild oxidative stress conditions," Free Radical Biology and Medicine, vol. 68, pp. 186-195, 2014.

[120] A. Pastore and F. Piemonte, "S-Glutathionylation signaling in cell biology: progress and prospects," European Journal of Pharmaceutical Sciences, vol. 46, no. 5, pp. 279-292, 2012.

[121] P. C. Sandoval, D. H. Slentz, T. Pisitkun, F. Saeed, J. D. Hoffert, and M. A. Knepper, "Proteome-wide measurement of protein half-lives and translation rates in vasopressinsensitive collecting duct cells," Journal of the American Society of Nephrology, vol. 24, no. 11, pp. 1793-1805, 2013.

[122] M. H. M. Shimizu, A. Danilovic, L. Andrade et al., "N-Acetylcysteine protects against renal injury following bilateral ureteral obstruction," Nephrology Dialysis Transplantation, vol. 23, no. 10, pp. 3067-3073, 2008.

[123] E. H. Bae, S. Y. Joo, S. K. Ma, J. Lee, and S. W. Kim, "Resveratrol attenuates 4-hydroxy-2-hexenal-induced oxidative stress in mouse cortical collecting duct cells," The Korean Journal of Physiology \& Pharmacology, vol. 20, no. 3, pp. 229-236, 2016.

[124] P. W. Cheung, L. Ueberdiek, J. Day, R. Bouley, and D. Brown, "Protein phosphatase 2C is responsible for VP-induced dephosphorylation of AQP2 serine 261," American Journal of Physiology-Renal Physiology, vol. 313, no. 2, pp. F404F413, 2017.

[125] P. I. Nedvetsky, V. Tabor, G. Tamma et al., "Reciprocal regulation of aquaporin-2 abundance and degradation by protein kinase A and p38-MAP kinase," Journal of the American Society of Nephrology, vol. 21, no. 10, pp. 1645-1656, 2010.

[126] M. M. Rinschen, M. J. Yu, G. Wang et al., "Quantitative phosphoproteomic analysis reveals vasopressin V2-receptordependent signaling pathways in renal collecting duct cells," Proceedings of the National Academy of Sciences, vol. 107, no. 8, pp. 3882-3887, 2010.

[127] G. Tamma, J. H. Robben, C. Trimpert, M. Boone, and P. M. T. Deen, "Regulation of AQP2 localization by S256 and S261 phosphorylation and ubiquitination," American Journal of Physiology-Cell Physiology, vol. 300, no. 3, pp. C636-C646, 2011.

[128] U. Hasler, V. Leroy, U. S. Jeon et al., "NF- $\kappa$ B modulates aquaporin-2 transcription in renal collecting duct principal cells," Journal of Biological Chemistry, vol. 283, no. 42, pp. 28095-28105, 2008. 
[129] E. Feraille, E. Dizin, I. Roth et al., "NADPH oxidase 4 deficiency reduces aquaporin-2 mRNA expression in cultured renal collecting duct principal cells via increased PDE3 and PDE4 activity," PLoS One, vol. 9, no. 1, article e87239, 2014.

[130] G. Tamma, M. Ranieri, A. Di Mise, M. Centrone, M. Svelto, and G. Valenti, "Glutathionylation of the aquaporin-2 water channel: a novel post-translational modification modulated by the oxidative stress," Journal of Biological Chemistry, vol. 289, no. 40, pp. 27807-27813, 2014.

[131] P. Portincasa, I. Cataldo, A. Maggio et al., "Modulation of aquaporins by dietary patterns and plant bioactive compounds," Current Medicinal Chemistry, vol. 24, 2017.

[132] D. Fiorentini, L. Zambonin, F. V. Dalla Sega, and S. Hrelia, "Polyphenols as modulators of aquaporin family in health and disease," Oxidative Medicine and Cellular Longevity, vol. 2015, Article ID 196914, 8 pages, 2015.

[133] M. Gao, S. Y. Zhu, C. B. Tan, B. Xu, W. C. Zhang, and G. H. $\mathrm{Du}$, "Pinocembrin protects the neurovascular unit by reducing inflammation and extracellular proteolysis in MCAO rats," Journal of Asian Natural Products Research, vol. 12, no. 5, pp. 407-418, 2010.

[134] B. Kumar, S. K. Gupta, T. C. Nag et al., "Retinal neuroprotective effects of quercetin in streptozotocin-induced diabetic rats," Experimental Eye Research, vol. 125, pp. 193-202, 2014.

[135] B. Kumar, S. K. Gupta, B. P. Srinivasan et al., "Hesperetin rescues retinal oxidative stress, neuroinflammation and apoptosis in diabetic rats," Microvascular Research, vol. 87, pp. 65$74,2013$.

[136] B. Zhang, Z. Liang, S. He et al., "The mechanism underlying alpinetin-mediated alleviation of pancreatitis-associated lung injury through upregulating aquaporin-1," Drug Design, Development and Therapy, vol. 10, p. 841, 2016.

[137] K. Saito, S. Mori, F. Date, and G. Hong, "Epigallocatechin gallate stimulates the neuroreactive salivary secretomotor system in autoimmune sialadenitis of MRL-Faslpr mice via activation of cAMP-dependent protein kinase A and inactivation of nuclear factor $\kappa \mathrm{B}$," Autoimmunity, vol. 48, no. 6, pp. 379-388, 2015.

[138] K. Oshio, H. Watanabe, Y. Song, A. S. Verkman, and G. T. Manley, "Reduced cerebrospinal fluid production and intracranial pressure in mice lacking choroid plexus water channel aquaporin-1,” The FASEB Journal, vol. 19, no. 1, pp. 76-78, 2005.

[139] C. Ji, C. Cao, S. Lu et al., "Curcumin attenuates EGF-induced AQP3 up-regulation and cell migration in human ovarian cancer cells," Cancer Chemotherapy and Pharmacology, vol. 62, no. 5, pp. 857-865, 2008.

[140] B. F. Wang, Z. W. Cui, Z. H. Zhong et al., "Curcumin attenuates brain edema in mice with intracerebral hemorrhage through inhibition of AQP4 and AQP9 expression," Acta Pharmacologica Sinica, vol. 36, no. 8, pp. 939-948, 2015.

[141] L. S. Yu, Y. Y. Fan, G. Ye et al., "Curcumin alleviates brain edema by lowering AQP4 expression levels in a rat model of hypoxia-hypercapnia-induced brain damage," Experimental and Therapeutic Medicine, vol. 11, no. 3, pp. 709-716, 2016.

[142] J. Zu, Y. Wang, G. Xu, J. Zhuang, H. Gong, and J. Yan, “Curcumin improves the recovery of motor function and reduces spinal cord edema in a rat acute spinal cord injury model by inhibiting the JAK/STAT signaling pathway," Acta Tistochemica, vol. 116, no. 8, pp. 1331-1336, 2014.
[143] I. Lozić, R. V. Hartz, C. A. Bartlett et al., "Enabling dual cellular destinations of polymeric nanoparticles for treatment following partial injury to the central nervous system," Biomaterials, vol. 74, pp. 200-216, 2016.

[144] M. Aliomrani, M. R. Sepand, H. R. Mirzaei, A. R. Kazemi, S. Nekonam, and O. Sabzevari, "Effects of phloretin on oxidative and inflammatory reaction in rat model of cecal ligation and puncture induced sepsis," DARU Journal of Pharmaceutical Sciences, vol. 24, no. 1, p. 15, 2016.

[145] F. J. Moller, P. Diel, O. Zierau, T. Hertrampf, J. Maass, and G. Vollmer, "Long-term dietary isoflavone exposure enhances estrogen sensitivity of rat uterine responsiveness mediated through estrogen receptor $\alpha$," Toxicology Letters, vol. 196, no. 3, pp. 142-153, 2010.

[146] Z. Zhong, B. Wang, M. Dai et al., "Carvacrol alleviates cerebral edema by modulating AQP4 expression after intracerebral hemorrhage in mice," Neuroscience Letters, vol. 555, pp. 24-29, 2013.

[147] E. J. Sohn, D. G. Kang, and H. S. Lee, "Protective effects of glycyrrhizin on gentamicin-induced acute renal failure in rats," Pharmacology \& Toxicology, vol. 93, no. 3, pp. 116122, 2003.

[148] Q. W. Ding, Y. Zhang, Y. Wang et al., "Functional vanilloid receptor-1 in human submandibular glands," Journal of Dental Research, vol. 89, no. 7, pp. 711-716, 2010.

[149] Y. Zhang, X. Cong, L. Shi et al., "Activation of transient receptor potential vanilloid subtype 1 increases secretion of the hypofunctional, transplanted submandibular gland," American Journal of Physiology-Gastrointestinal and Liver Physiology, vol. 299, no. 1, pp. G54-G62, 2010.

[150] I. D. Weiner, "New insights into the molecular regulation of urine concentration," American Journal of Physiology-Renal Physiology, vol. 311, no. 1, pp. F184-F185, 2016.

[151] M. C. Papadopoulos and A. S. Verkman, "Aquaporin water channels in the nervous system," Nature Reviews. Neuroscience, vol. 14, no. 4, pp. 265-277, 2013.

[152] T. L. Tran, S. Hamann, and S. Heegaard, "Aquaporins in the eye," Advances in Experimental Medicine and Biology, vol. 969, pp. 193-198, 2017.

[153] P. Portincasa and G. Calamita, "Water channel proteins in bile formation and flow in health and disease: when immiscible becomes miscible," Molecular Aspects of Medicine, vol. 33, no. 5-6, pp. 651-664, 2012.

[154] L. Pei, G. Yang, J. Jiang et al., "Expression of aquaporins in prostate and seminal vesicles of diabetic rats," The Journal of Sexual Medicine, vol. 10, no. 12, pp. 2975-2985, 2013.

[155] G. Cui, M. M. Staron, S. M. Gray et al., "IL-7-induced glycerol transport and TAG synthesis promotes memory CD8+ T cell longevity,” Cell, vol. 161, no. 4, pp. 750-761, 2015.

[156] V. Rabolli, L. Wallemme, S. Lo Re et al., "Critical role of aquaporins in interleukin $1 \beta$ (IL-1 $\beta$ )-induced inflammation," The Journal of Biological Chemistry, vol. 289, no. 20, pp. 1393713947, 2014.

[157] M. G. Song, S. Y. Hwang, J. I. Park, S. Yoon, H. R. Bae, and J. Y. Kwak, "Role of aquaporin 3 in development, subtypes and activation of dendritic cells," Molecular Immunology, vol. 49, no. 1-2, pp. 28-37, 2011.

[158] A. Rodriguez, R. A. Marinelli, A. Tesse, G. Fruhbeck, and G. Calamita, "Sexual dimorphism of adipose and hepatic aquaglyceroporins in health and metabolic disorders," Frontiers in Endocrinology, vol. 6, 2015. 
[159] L. R. Soria, J. Marrone, G. Calamita, and R. A. Marinelli, "Ammonia detoxification via ureagenesis in rat hepatocytes involves mitochondrial aquaporin-8 channels," Hepatology, vol. 57, no. 5, pp. 2061-2071, 2013.

[160] M. Yasui, S. M. Zelenin, G. Celsi, and A. Aperia, "Adenylate cyclase-coupled vasopressin receptor activates AQP2 promoter via a dual effect on CRE and AP1 elements," The American Journal of Physiology, vol. 272, no. 4, pp. F443F450, 1997.

[161] A. S. Verkman, "More than just water channels: unexpected cellular roles of aquaporins," Journal of Cell Science, vol. 118, no. 15, pp. 3225-3232, 2005.

[162] P. Agre, “Aquaporin water channels (Nobel Lecture)," Angewandte Chemie International Edition, vol. 43, no. 33, pp. 4278-4290, 2004.

[163] S. Saadoun, M. C. Papadopoulos, M. Hara-Chikuma, and A. S. Verkman, "Impairment of angiogenesis and cell migration by targeted aquaporin-1 gene disruption," Nature, vol. 434, no. 7034, pp. 786-792, 2005.

[164] L. Tie, D. Wang, Y. Shi, and X. Li, "Aquaporins in cardiovascular system," Advances in Experimental Medicine and Biology, vol. 969, pp. 105-113, 2017.

[165] H. B. Moeller, C. H. Fuglsang, and R. A. Fenton, "Renal aquaporins and water balance disorders," Best Practice \& Research Clinical Endocrinology \& Metabolism, vol. 30, no. 2, pp. 277288, 2016.

[166] E. Benavente and S. Paira, "Neuromyelitis Optica-AQP4: an update," Current Rheumatology Reports, vol. 13, no. 6, pp. 496-505, 2011.

[167] Y. Liu, D. Promeneur, A. Rojek et al., "Aquaporin 9 is the major pathway for glycerol uptake by mouse erythrocytes, with implications for malarial virulence," Proceedings of the National Academy of Sciences, vol. 104, no. 30, pp. 1256012564, 2007.

[168] M. C. Papadopoulos and S. Saadoun, "Key roles of aquaporins in tumor biology," Biochimica et Biophysica Acta (BBA) - Biomembranes, vol. 1848, no. 10, pp. 2576-2583, 2015.

[169] R. Bernardino, R. Marinelli, A. Maggio et al., "Hepatocyte and sertoli cell aquaporins, recent advances and research trends," International Journal of Molecular Sciences, vol. 17, no. 12, 2016. 


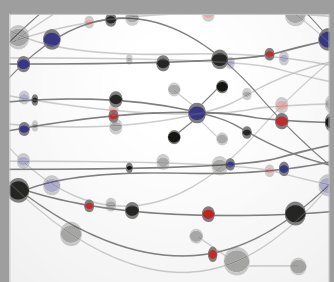

The Scientific World Journal
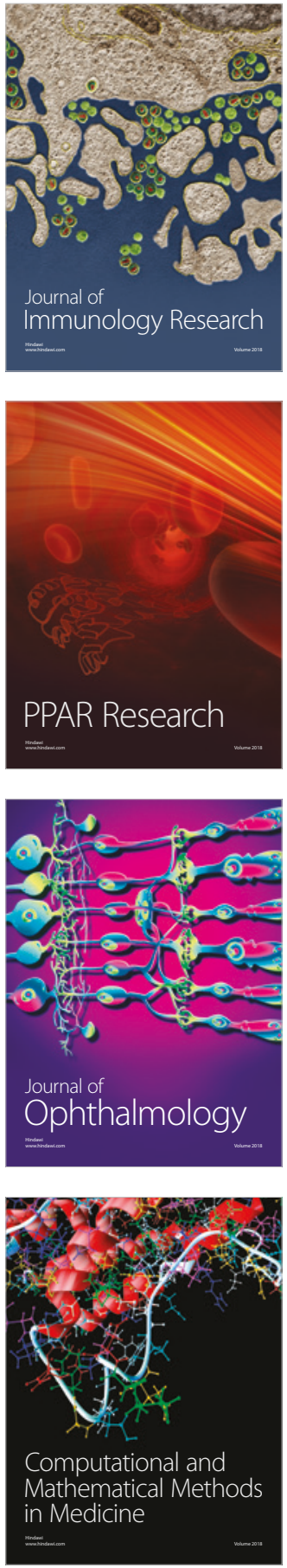

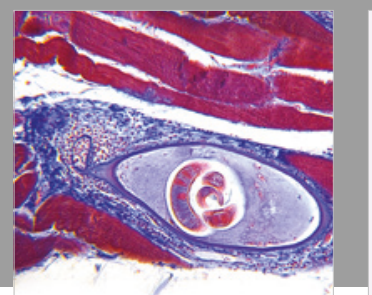

Gastroenterology Research and Practice

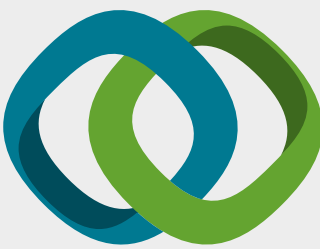

\section{Hindawi}

Submit your manuscripts at

www.hindawi.com
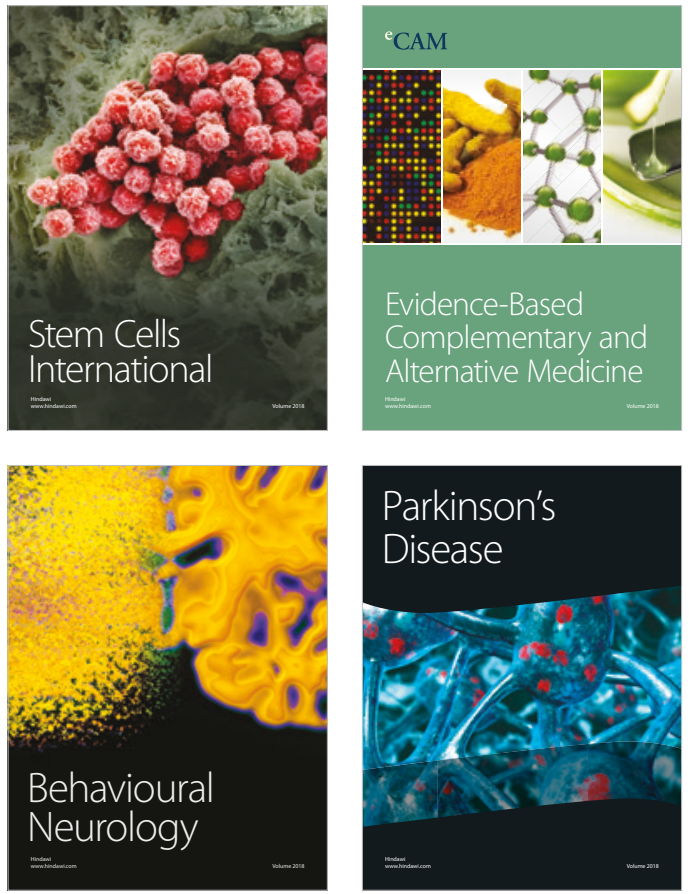

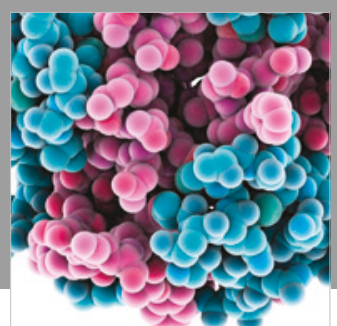

ournal of

Diabetes Research

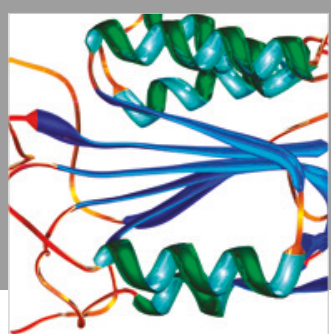

Disease Markers
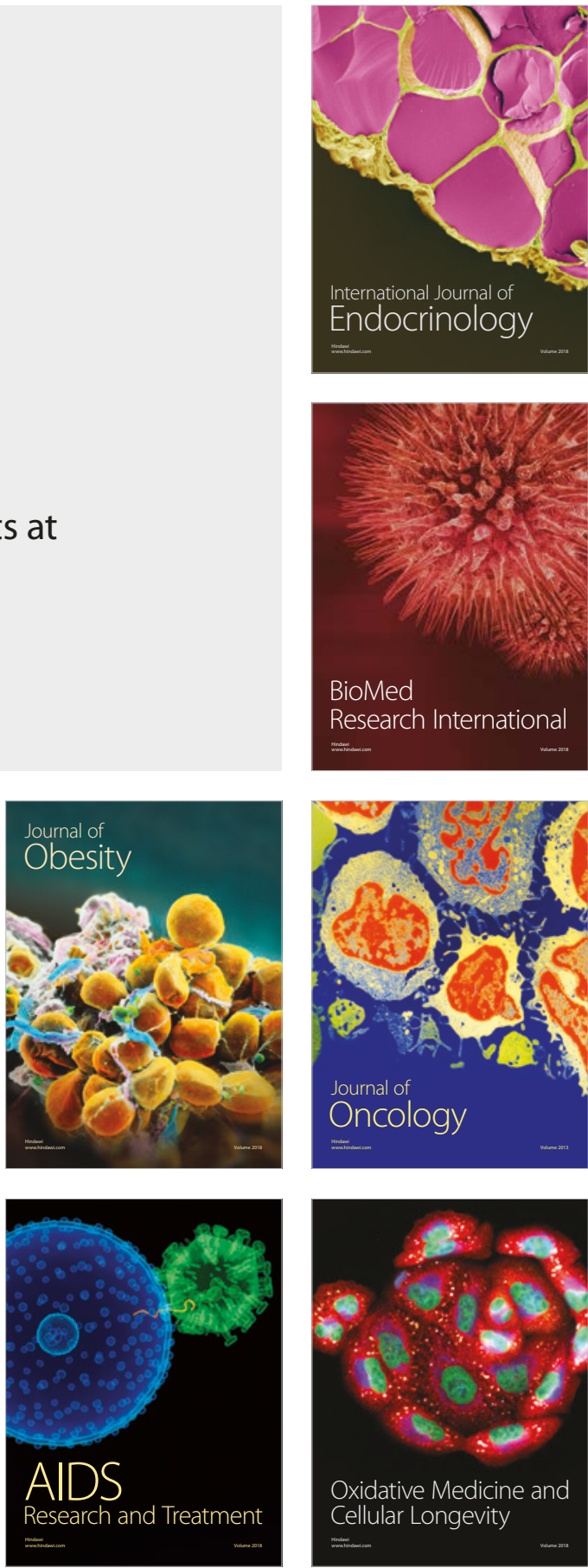